SALINERO, Sebastián: "El concurso de delitos en la práctica de la judicatura chilena. Una

aproximación empírica desde el estudio de casos simulados".

Polít. Crim. Vol. 16, № 31 (Julio 2021), Art. 2, pp. 30-61

[http://politcrim.com/wp-content/uploads/2021/04/Vol16N31A2.pdf]

\title{
El concurso de delitos en la práctica de la judicatura chilena. Una aproximación empírica desde el estudio de casos simulados*
}

\section{The Concurrent Offences in the Practice of the Chilean Sentencing. An Empirical Approach from the Study of Simulated Cases}

\author{
Sebastián Salinero Echeverría \\ Abogado, Magíster en Derecho Penal de la Universidad de Talca. \\ Doctor en Derecho de la Universidad de Lérida, España. \\ Profesor de Derecho Penal y Criminología de la Universidad de Talca. \\ ssalinero@utalca.cl \\ https://orcid.org/0000-0003-4988-8357
}

\section{Resumen}

El trabajo, mediante una metodología cualitativa consistente en solución de casos simulados y entrevistas semi-estructuradas, se aboca al estudio del sentencing del concurso de delitos por parte de jueces chilenos. El estudio plantea como objetivos: comprender el proceso de decisión y motivación para cuestiones concursales, y saber si existen fuentes informales determinantes en ese proceso; conocer e identificar las cuestiones observadas por los jueces para determinar una unidad o pluralidad delictiva; y determinar la complejidad que presentan los concursos en la labor de juzgamiento. Entre los hallazgos destaca en que aparentemente concurre una comprensión especial de la temática concursal por parte de los jueces, basada en la experiencia y las propias definiciones que se tiene de las instituciones concursales. También se prueba la problemática que presenta el concurso, lo que se corrobora en la dispersión de soluciones de los jueces frente a un mismo caso.

Palabras clave: juzgamiento, estudio de casos, entrevistas, concurso de delitos.

\begin{abstract}
The work through a qualitative methodology, consisting of a solution of simulated cases and semi-structured interviews, is devoted to the study of the sentence of the conjunction of crimes by Chilean judges. The study aims to understand the decision and motivation process for bankruptcy issues, and to know if there are determining informal sources in this process; know and identify the issues observed by the judges to determine a unit or plurality offenses; and determine the complexity of the competitions in the judging work. Among the findings, it stands out that there appears to be a special understanding of the bankruptcy issue by the

\footnotetext{
${ }^{*}$ El presente trabajo está asociado a la ejecución del Proyecto FONDECYT Regular N ${ }^{\circ} 1170276$ a cargo del profesor Dr. Francisco Maldonado Fuentes, donde el autor de este trabajo es co-investigador. También quisiera agradecer la valiosa colaboración de Sebastián Galleguillos Agurto.
} 
judges, based on experience and the definitions of bankruptcy institutions themselves. The problems presented by the contest in general are also tested, which is corroborated in the dispersion of solutions of the judges in the same case.

Keywords: Sentencing, case studies, interviews, conjunction of crimes.

\section{Introducción}

La teoría de los concursos, de manera inusual, ha llamado la atención de la doctrina chilena en el último tiempo. Probablemente las razones de tal interés obedezcan a la larga desatención que esta temática ocupó en nuestra historia jurídica o al impacto en la respuesta penal que puede generar la adscripción a las diversas teorías que la conforman. En base a una metodología que podemos tildar de homogénea, el abordaje de los concursos ha sido el propio de la dogmática penal, esto es, el jurídico abstracto. El componente basado en la experiencia prácticamente no existe y el comentario jurídico de sentencias sobre esta narrativa, podemos decir que no corre mejor suerte.

La importancia de los concursos, entre otras, se encuentra en la esfera práctica a nivel penológico. Saber si existe unidad o pluralidad de acción o hechos determina la regla de sanción y, en concreto, la pena aplicable al justiciable.

Por su parte, alcanzar una comprensión adecuada del comportamiento judicial, mediante el conocimiento empírico de la labor de juzgamiento de los denominados concursos de delitos, el que si bien en lo jurídico pareciera ser un proceso sin mayor dificultad, en el análisis de sus supuestos de procedencia, presenta complejidades que no pueden ser comprendidas solo bajo un análisis normativo; además reviste un interés importante, incluso más allá del académico, pues es clave para la reforma del derecho, toda vez que puede proporcionar elementos para el conocimiento del problema desde otra óptica.

Mediante una metodología novedosa para el contexto chileno, consistente en el estudio de casos simulados y entrevistas a actores relevantes (jueces), ambos dentro del marco de la denominada metodología cualitativa, se persigue lograr como objetivo general explorar el proceso de juzgamiento o sentencing de los concursos de delitos por parte de los jueces. En particular, se busca comprender el proceso de decisión y motivación para cuestiones concursales, saber si existen fuentes informales determinantes en ese proceso, ${ }^{1}$ conocer e identificar las cuestiones observadas por los jueces para determinar una unidad o pluralidad delictiva, y deteminar la complejidad que presentan los concursos en la labor de juzgamiento.

El artículo pone el acento en el análisis descriptivo más que normativo, pero también somete a discusión cuestiones normativas y se proponen algunas modestas y generales sugerencias. El trabajo se traza en tres grandes partes. La primera relativa a la determinación del marco de referencia, donde se desarrolla en la forma más objetiva posible, pero de manera breve, la teoría concursal; una segunda parte donde se presenta la metodología y los objetivos de la investigación, precedida del estado del arte - teórico y empírico - en lo que a juzgamiento

\footnotetext{
1 En este estudios se utiliza la expresión "fuentes informales", como sinónimo también de "fuentes
} extralegales", "ideología" o lisa y llanamente "creencias personales". 


\section{Polít. Crim. Vol. 16, № 31 (Julio 2021), Art. 2, pp. 30-61 [http://politcrim.com/wp-content/uploads/2021/04/Vol16N31A2.pdf]}

se refiere (sentencing); y una tercera parte donde se exponen los resultados, para terminar con el análisis del contenido.

\section{El concurso de delitos en general}

\subsection{Consideraciones generales}

Es relativamente pacífico en la doctrina que un delito se comete cuando se realiza una sola vez (frecuencia) la conducta descrita en la ley (tipo penal). Para este caso, la consecuencia penal también es fácil de determinar y, no es otra, que aplicar la pena que el delito tiene asignada en la propia parte especial del derecho punitivo.

Sin embargo, la doctrina no es pacífica a la hora de entender si se pone en peligro o se lesiona bienes jurídicos por una o varias acciones, y si en estos casos estamos en presencia de uno o varios delitos. ${ }^{2}$ Es complejo saber cuando estamos en presencia de una sola acción o — para otros autores - un hecho, saber cuándo estamos frente a una pluralidad de acciones o también hechos; resolver si acción y hecho son equivalentes. ${ }^{3}$

Un delito se puede configurar a partir de una pluralidad o suma de acciones o hechos (las y los que pueden ser distintas y distintos), ni tampoco que una sola acción o hecho pueda satisfacer las exigencias normativas de una pluralidad de delitos. ${ }^{4}$ Esta idea viene a expresar lo que se conoce tradicionalmente como unidad delictiva, la que puede ser natural o jurídica. Siendo la primera, en su dimensión tradicional, cuando se realiza solo la acción descrita en la norma legal ${ }^{5}$, pero también lo es cuando la conducta está constituida objetivamente, en la materialidad, por varias actividades que, valoradas desde el propósito o finalidad del autor, conforman una sola acción. ${ }^{6}$ En cambio, hay unidad jurídica cuando una pluralidad de actos es valorada como una unidad por el respectivo tipo penal. ${ }^{7}$

El problema deviene tratándose de pluralidad de delitos, también conocido como concurso, que se presenta cuando a una persona se le puede imputar la realización de un supuesto de hecho de diversos tipos penales — a lo menos dos- o la reiteración (frecuencia) de uno mismo. ${ }^{8}$ Aquí la problemática viene dada en dos aspectos. Por una parte, en poder determinar si realmente estamos frente a una pluralidad de infracciones y, con ello, afirmar el concurso $\mathrm{y},{ }^{9}$ por otro lado, en determinar la regla de sanción. Saber si la consecuencia penal es

${ }^{2}$ GARRIDO (2007), p. 435.

${ }^{3}$ NOVOA (2010), p. 221; ETCHEBERRY (2004), p. 109. Hablan de unidad de hecho; CURY (2005), p. 650; GARRIDO (2007), p. 436. Este último autor al referirse a la unidad de acción señala que acción y hecho no son equivalentes.

${ }^{4}$ VIVES(1981), p.7.

${ }^{5}$ POLITOFF et al. (2006), p. 452; CURY (2005), p. 650.

${ }^{6}$ GARRIDO (2007), p. 436; ETCHEBERRY (2004), p. 109 y ss.; CURY (2005), p. 650 y ss. Cury agrega que la unidad natural de acción ha de ser tanto física como psíquica (objetiva y subjetiva); JESCHECK y WEIGEND (2002), p. 763 y ss. La unidad jurídica se presenta cuando hay una serie de actos que son valorados como una unidad por el respectivo tipo penal.

${ }^{7}$ JESCHECK y WEIGEND (2002), p. 766; GARRIDO (2007), p. 437; CURY (2005), p. 651; ETCHEBERRY (2004), p. 110. Este último autor distingue entre especial estructura del tipo y unidad de resultado.

${ }^{8}$ POLITOFF et al. (2006), p. 445.

${ }^{9}$ SANZ (1986), p. 111. 
acumulativa a las diversas infracciones penales (suma de las diversas penas), o bien la solución punitiva es menos estricta a esa regla de sanción. ${ }^{10}$

Dicho lo anterior, no es complejo concluir que la sistematización de la teoría concursal se estructura, en su vertiente tradicional, trazando una línea divisoria entre los casos de unidad delictiva (natural o jurídica) y los casos propiamente concursales. ${ }^{11}$

\subsection{Concurso real, ideal y medial}

Cuando la sanción es más gravosa, estamos frente a lo que se conoce como acumulación material de penas, que no es otra cosa que la suma de las diversas penas concurrentes a las infracciones penales cometidas y, es por así decirlo, la regla general recogida en la legislación chilena. Su contenido positivo se encuentra en el denominado concurso real o material, regulado en el inc $1^{\circ}$ del artículo 74 del Código penal, que establece: "al culpable de dos o más delitos se le impondrán todas las penas correspondientes a las diversas infracciones". De esta manera, el sujeto culpable responde conjuntamente de todas las infracciones cometidas, cuyas penas se suman en el sentido aritmético de la expresión. Este concurso se clasifica en homogéneo o heterogéneo en consideración a la identidad de la naturaleza de las infracciones cometidas. Si se trata de una misma naturaleza será homogéneo como ocurre frente a dos hurtos y, en caso contrario, será heterogéneo como por ejemplo el homicidio y el robo. ${ }^{12}$

El principio de acumulación material tiene excepciones que se traducen en un efecto morigerado de la consecuencia penal, y obedece a lo que parte de la doctrina define como principio de pena unitaria, ${ }^{13}$ donde se determina una sola consecuencia penal, independiente del número de infracciones legales cometidas o de la naturaleza de las que concurren en el caso concreto.

La primera de estas excepciones y con tradición positiva en nuestra legislación es lo que se conoce como concurso ideal y el medial respectivamente, ambos contenidos en la misma disposición normativa, artículo 75 del Código penal, que tiene una regla de solución consistente en aplicar solo la pena del delito más grave. El concurso ideal se da cuando un mismo hecho constituye dos o más delitos, y el concurso medial se presenta cuando uno es medio necesario para la comisión de otro delito. En el concurso ideal se suelen distinguir dos modalidades: el homogéneo que se evidencia con el clásico ejemplo de la muerte de varias personas producto del estallido de una sola bomba, y el heterogéneo cuyo ejemplo colocado por la propia comisión redactora del código, se da entre el incesto y la violación. ${ }^{14}$ Los criterios utilizados doctrinariamente para arribar a esta calificción de concurso ideal son de tres órdenes de consideraciones: por un lado, una pluralidad de variantes asociadas al contexto y a razones naturalísticas tributarias de la perspectiva espacio-temporal (como el contexto, la unidad de situación o el carácter ininterrumpido de la ejecución); por otro las

${ }^{10}$ JESCHECK y WEIGEND (2002), p. 761.

${ }^{11}$ MALDONADO (2013), pp. 565-567.

${ }^{12}$ NOVOA (2010), p. 224; POLITOFF et al. (2006), p.447; GARRIDO (2007), p. 447; CURY (2005), p. 659; ETCHEBERRY (2004), p. 115; JESCHECK y WEIGEND (2002), p. 782.

${ }^{13}$ JESCHECK y WEIGEND (2002), p. 762.

${ }^{14}$ NOVOA (2010), p. 229; POLITOFF et al. (2006), p.447; GARRIDO (2007), p. 452; CURY (2005), p. 663; ETCHEBERRY (2004), p. 118; JESCHECK y WEIGEND (2002), p. 773. 


\section{Polít. Crim. Vol. 16, № 31 (Julio 2021), Art. 2, pp. 30-61 [http://politcrim.com/wp-content/uploads/2021/04/Vol16N31A2.pdf]}

referidas a un criterio externo o construido, como sucede con la identificación de una unidad tras un efecto tangible (aproximación objetiva ) o una determinada dirección de la voluntad (aproximación subjetiva ); otros, en tercer término, procuran delimitar la ejecución unitaria bajo la idea de que no ha sido para el autor resolver la ejecución de los delitos en forma separada (evitabilidad conjunta y concurrencia necesaria o indivisible ). ${ }^{15} \mathrm{~A}$ su vez, el concurso medial o también conocido como concurso ideal impropio, el que verdaderamente es un concurso real que se produce cuando existe una conexión ideológica entre los delitos concurrentes, que ocurre por ejemplo cuando se falsifica un documento para su posterior uso malicioso. ${ }^{16}$ El criterio aceptado por la doctrina para calificar este concurso es que uno de los delitos debe ser medio necesario para cometer el otro, lo que implica evaluar esta característica en el caso concreto y conforme las circunstancias concomitantes. ${ }^{17}$

En relación con el concurso ideal, la pena mayor asignada al delito más grave no siempre será más benevolente que la simple acumulación material, y es por ello por lo que alguna doctrina y jurisprudencia sostienen la posibilidad de aplicar, en definitiva y de manera alternativa, la norma más beneficiosa (arts. 74 o 75$).{ }^{18}$

\subsection{Casos de unidad delictiva}

Como señalamos previamente, los casos de unidad delictiva pueden ser de carácter natural o jurídica. Ante estos casos, por regla general, no estamos frente a verdaderos problemas concursales $^{19}$, sino más bien a problemas de interpretación legal.

La unidad natural importa entender que estamos frente a un solo delito aún cuando el número de actividades que lo configura sean variadas. (hay un delito de lesiones pese a que la víctima sufrió múltiples golpes de pies y manos en diversas partes de su cuerpo). Aquí la serie de actividades que puede existir (porque también puede ser solo una) configuran en el marco de la tipicidad la conducta prohibida o esperada. A su vez, estamos frente a una unidad jurídica cuando existe una serie de actos que podrían configurarse independientemente como injustos típicos, peros existe una unidad objetivo y/o subjetiva entre ellos que permite tenerlos e definitiva como un solo delito. ${ }^{20}$

\footnotetext{
${ }^{15}$ Una buena síntesis, auque crítica, puede verse en MALDONADO, (2020), p. 13 y ss.

${ }^{16}$ NOVOA (2010), p. 234; POLITOFF et al. (2006), p. 448; GARRIDO (2007), pp. 448 - 450; CURY (2005), p. 662.

${ }^{17}$ NOVOA (2010), pp. $234-235$.

18 GARRIDO (2007), p. 437; ETCHEBERRY (2004), pp. 121 - 122; aparentemente en el mismo sentido
} POLITOFF et al. (2006), p.451.

${ }^{19}$ POLITOFF et al. (2006), p.452.

${ }^{20}$ MALDONADO, (2020), p. 10. Para determinar la unidad lo más usual en la doctrina chilena: "ha sido el recurso a factores naturalísticos (como la unidad del contexto fáctico, una cierta progresión en la lesión o la inmediatez o proximidad espacio-temporal, etc.), propuesto incluso por autores que acertadamente los han descartado a nivel general. Además, se recurre a la identificación de una intensión o vinculación subjetiva global; a la constatación de uno o varios resultados típicos, o a la lesividad concreta para un bien jurídico en particular; en especial cuando se trata de un bien de carácter personalísimo, con resultados que siempre se muestran similares, en cuanto insatisfactorios como criterio general. Lo único en que todas las propuestas coinciden es en la necesidad de contar con un criterio adicional que se identifica, en todos los casos, con la posibilidad de sostener una única acción (y, en ese sentido, una única ejecución o realización) que cuente como (única) ejemplificación de una determinada clase de acción." 
Uno de estos casos de unidad delictiva, que obedece también al principio de pena unitaria, son los de exasperación de penas o también conocidos como de acumulación jurídica. Son casos que, si bien existe una agravación de pena, esta se presenta como morigerada ante la simple acumulación material. Aquí estamos frente a casos de concurrencia reiterada de delitos, los cuales pueden ser de dos especies, por una parte, los casos de reiteración de delitos y, por otro lado, los casos de hurto reiterado.

La reiteración de delitos está recogida en el artículo 351 del Código Procesal Penal, y está referida a la reiteración de crímenes o simple delitos de la misma especie, o misma falta. Por la misma especie se entendió tradicionalmente aquellos delitos que eran tratados bajo un mismo título o la ley que los describe, tal como lo preceptúa el —aún vigente — artículo 509 del Código de Procedimiento Penal, cuestión que sucedería con el hurto y robo por ejemplo, pero plantea también paradojas o inconexiones lógicas que han sido objeto de críticas, ${ }^{21}$ como podría ocurrir a propósito del homicidio y el tráfico de migrante (Título VIII). ${ }^{22}$ Ahora la situación, a lo menos normativamente para ser calificado de la misma especie queda reducida a delitos que afecten el mismo bien jurídico. Cuestión que también ha traído problemas interpretativos y ha sido objeto de critica por parte de la doctrina. ${ }^{23}$

La regla de sanción en la reiteración de delitos es binaria y se atiende a si las diversas infracciones se pueden estimar o no como un solo delito. ${ }^{24}$ En el caso que se pueda afirmar un solo delito respecto de las infracciones concurrentes, la consecuencia penal es imponer la pena de este delito, aumentado en uno o dos grados. A la inversa, esto es, cuando las diversas infracciones no pueden estimarse como un solo delito, se aplica la pena de aquella que, considerada aisladamente, con las circunstancias del caso, tenga asignada una pena mayor, aumentada en uno o dos grados. ${ }^{25}$ Para cualquiera que sea la respuestaa, el aumento de grado en la sanción es obligatoria para el juzgador, no así la cuantía del aumento.

El otro caso es el de la reiteración del delito de hurto, el cual se rige por una regla especial prevista en el artículo 451 del Código penal. La regla de sanción, de absorción agravada, obliga a sumar el importe del total de lo sustraído para así determinar, conforme a las diversas graduaciones que realiza el tipo penal de hurto en el artículo 446, la pena a imponer, pero siempre en su grado superior. ${ }^{26}$

También son casos de unidad jurídica los denominados delitos complejos que, como bien es sabido, son casos en que el legislador reúne en la descripción del tipo penal los supuestos de dos o más figuras penales que son individualmente punibles. El ejemplo paradigmático lo constituye el delito de robo calificado ( $\operatorname{art} 433 \mathrm{~N}^{\mathrm{o}} 1$ robo con homicidio) y robo con violencia $(\operatorname{art} 436) .^{27}$

\footnotetext{
${ }^{21}$ NOVOA (2010), p. 228; GARRIDO (2007), p. 449.

22 POLITOFF et al. (2006), p.466.

${ }^{23}$ POLITOFF et al. (2006), p.467; CURY (2005), p. 661.

${ }^{24}$ Sobre la discusión al respecto, puede verse: MALDONADO (2013), pp. 549-607; OLIVER (2013), pp.167188.

${ }^{25}$ MALDONADO (2013), pp. 599-603.

${ }^{26}$ POLITOFF et al. (2006), p.466; CURY (2005), p. 663.

${ }^{27}$ POLITOFF et al. (2006), p.455; GARRIDO (2007), p. 437; ETCHEBERRY (2004), p. 110.
} 
Los casos de delito permanente son otro ejemplo de unidad jurídica. En ellos el estado de antijuridicidad y consumación se prolonga en el tiempo (por horas, días, meses o años), como ocurre con el secuestro y la sustracción de menores (arts. 141 y 142). No obstante el tiempo transcurrido o que subsista el estado de antijuridicidad, nos encontraremos frente a un solo delito. ${ }^{28}$

Por su parte, otra categoría de delito que adscribe a la unidad delictiva con carácter jurídica es el denominado delito continuado, sin reconocimiento normativo en nuestro ordenamiento, pero con profundo arraigo en la jurisprudencia de los tribunales y en la doctrina nacional. Estamos frente a un solo delito, aún cuando exista una serie de conductas que individualmente configura un delito por si sola, cuando existe unidad (identidad) de autor y de tipo penal o de bienes jurídicos semejantes, durante cierto lapso prolongado de tiempo y con un propósito común. ${ }^{29}$

Finalmente, existe otra serie de delitos que comparten la característica de considerarse jurídicamente como una unidad delictiva, como son: los delitos de emprendimiento, los delitos habituales y los delitos compuestos. Todos los cuales, no viene al caso detallar mayormente en este trabajo por superar su objeto. ${ }^{30}$

\subsection{El concurso aparente de leyes}

Pese al nombre, aquí en realidad no hay un concurso, sino que nos encontramos ante un problema de interpretación de leyes penales que colisionan para un caso en concreto, y se soluciona a través de ciertos principios que se rechazan recíprocamente en aras de la subsistencia de un solo tipo penal, denominados en general como especialidad, consunción, subsidariedad, $\mathrm{o}$ alternatividad. ${ }^{31}$

Frente a la casuística que nos presenta la realidad, el concurso aparente podría ser confundido con el concurso ideal (incluso el medial), pues en términos generales en ambos existe una sola actividad delictiva. Sin embargo, la diferencia viene dada porque en el concurso ideal la conducta desplegada por el agente configura simultáneamente dos o más tipos penales que no se rechazan recíprocamente. A su vez, en el concurso aparente opera una mecánica inversa, frente a una sola actividad delictiva los tipos penales concurrentes se restan recíprocamente, por razones lógicas o materiales como es el infringir el principio non bis in ídem.

\subsubsection{Principio de especialidad}

\footnotetext{
${ }^{28}$ POLITOFF et al. (2006), p. 453; GARRIDO (2007), p. 437; ETCHEBERRY (2004), p. 111.

${ }^{29}$ NOVOA (2010), p. 236; POLITOFF et al, (2006), p.452; GARRIDO (2007), p. 440; CURY (2005), p. 653; ETCHEBERRY (2004), p. 110; JESCHECK y WEIGEND (2002), p. 769.

${ }^{30}$ Para un mejor examen véase, entre otros: POLITOFF et al. (2006), pp.455 y ss.

${ }^{31}$ NOVOA (2010), p. 247; POLITOFF et al. (2006), p. 456; GARRIDO (2007), p. 435; CURY (2005), p. 667; ETCHEBERRY (2004), p. 123; JESCHECK y WEIGEND (2002), p. 788. Una problematización sobre la concepción tradicional puede verse en MALDONADO (2020), p. 3 y ss.
} 
En caso de concurrir dos normas penales respecto de un mismo supuesto fáctico, nos encontraremos frente a relación de especialidad cuando una de ellas describe el mismo presupuesto que la otra, pero lo hace con mayor especificidad o particularidad, de manera de contener en su descripción todos los elementos típicos de la otra ${ }^{32}$ Como manifiesta Garrido Montt, de cierta manera existe una relación de género a especie, que impide que puedan concurrir a un mismo hecho ambas de manera coetánea y donde la norma especial es preferente a la norma general. ${ }^{33}$ Obedece al tradicional principio lex specialis deraogat legi generali (la ley especial deroga a la ley general). ${ }^{34}$

El ejemplo por antonomasia que caracteriza a este principio es el que se genera a propósito del homicidio doloso de un pariente. Al respecto, concurre el delito de parricidio y el de homicidio - simple o calificado-, pero el primero por contener una descripción más detallada o particular (singularización del parentesco entre víctima y victimario) desplaza al tipo base de homicidio.

\subsubsection{Principio de subsidiariedad}

Este principio ha sostenido la doctrina que se confunde con el de especialidad o consunción ${ }^{35}$. Sin perjuicio del valor que le reconocen algunos autores para situaciones no cubiertas por esos otros principios. ${ }^{36} \mathrm{Su}$ valor radica en que respecto de un hecho que concurren dos tipos penales, la preferencia de uno de ellos, desplazando al otro, se produce por expresa - y aún tacita $^{37}$ — disposición de la ley.

La estructura lógica de la subsidiariedad no responde a la idea de subordinación sino a la de coincidencia parcial (interferencia). ${ }^{38}$

1.4.3. Principio de consunción o absorción

El principio de consunción o de absorción consiste en optar por la norma jurídico penal que valorativamente - no lógicamente - y por su extensión o amplitud comprenda a otra, que tiene suficiencia de poder ser aplicada simultáneamente, por abarcar de igual manera el hecho concreto. ${ }^{39}$ En otras palabras, la ley al establecer la penalidad en una figura penal ya ha tomado en consideración la gravedad de otras conductas punibles que también la acompañan. ${ }^{40}$ Como señala Etcheberry, este acompañamiento puede ser de manera previa, como medios, como etapas de desarrollo, como consecuencia, etc. ${ }^{41}$ Así las cosas, solo se

${ }^{32}$ NOVOA (2010), p. 253; POLITOFF et al. (2006) p.458; CURY (2005), p. 668; ETCHEBERRY (2004), p. 123

${ }^{33}$ GARRIDO (2007), p. 458.

${ }^{34}$ JESCHECK y WEIGEND (2002), p. 790.

${ }^{35}$ ETCHEBERRY (2004), p.127.

${ }^{36}$ POLITOFF et al. (2006), p.459.

37 GARRIDO (2007), p. 460, quien sin señalar ejemplos indica que también puede ser de manera tacita; aparentemente la tacita está más bien ligada a la interpretación de contexto de varias normas JESCHECK y WEIGEND (2002), p. 791; CURY (2005), p. 670.

38 JESCHECK y WEIGEND (2002), p. 791.

39 JESCHECK y WEIGEND (2002), p. 792.

${ }^{40}$ NOVOA (2010), p. 255; POLITOFF et al. (2006) pp.461 y 462; GARRIDO (2007), p. 458; CURY (2005), p. 669.

${ }^{41}$ ETCHEBERRY (2004), p.124. 


\section{Polít. Crim. Vol. 16, № 31 (Julio 2021), Art. 2, pp. 30-61 [http://politcrim.com/wp-content/uploads/2021/04/Vol16N31A2.pdf]}

debe considerar la figura principal, y la o las accesorias desaparecen por encontrarse ya comprendidas en ella. Cuanto hablamos de encontrarse comprendidas, hacemos alusión no al carácter literal que un injusto se contenga explícitamente en la descripción típica de otro, pues en ese caso se resuelve conforme el principio de especialidad, sino a que esa figura accesoria sea parte en su contenido valorativo, de manera que no pueda lícitamente ponderarse sin infringir el principio non bis in ídem. ${ }^{42}$

Para terminar, en la actualidad existen posiciones que califican a la consunción como criterio -no principio- del concurso aparente, delimitando su contenido a través de su consideración como regla de preferencia, la que operaría frente a supuestos en que el no desplazamiento de una de las normas de sanción de los tipos penales concurrentes infringe el principio non bis in ídem. Estos autores distinguen entre aplicabilidad interna y externa de normas penales, dependiendo de si existe una norma jurídica que obligue al juzgador a usar otra norma para resolver la cuestión (en la externa existe la obligación), defendiendo la tesis de que los supuestos de concurso aparente deben resolverse en sede de aplicabilidad externa de los tipos penales concurrentes ${ }^{43}$ pese a que hay una importante doctrina que lo sitúa como una cuestión de aplicabilidad interna. ${ }^{44}$

\subsubsection{Principio de alternatividad}

Se trata de un principio criticado por la doctrina, en tanto su espectro de acción está más bien absorbido por el principio de especialidad o de consunción. Este principio viene a solucionar situaciones en que un supuesto de hecho es valorado de manera distinta por más de una norma penal o una misma norma prevé una pluralidad de hipótesis. Si esas distintas normas penales establecen la misma pena, se puede recurrir a cualquiera de ellas desplazándose la restante (porque de lo contrario vulnera el non bis in ídem). Ahora, es diferente cuando las normas penales establecen penas distintas, en cuyo caso se debe preferir la pena más grave, desapareciendo la otra. ${ }^{45}$

\section{El juzgamiento en general}

\subsection{Aproximaciones teóricas}

A lo largo de la historia, el sistema de justicia transitó desde la autocomposición o justicia de propia mano, a la heterocomposición que implica la actuación de un tercero. Este tercero es un órgano imparcial con respecto a las partes involucradas en el conflicto, que asumiendo la representación del Estado moderno, "soluciona" o procede a "juzgar" el conflicto sometido a la jurisdicción de los jueces.

\footnotetext{
${ }^{42}$ GARRIDO (2007), pp. 458 - 459; ETCHEBERRY (2004), p. 125.

${ }^{43}$ ARTAZA et al. (2019), passim.

${ }^{44}$ Para un mejor entendimiento, véase el desarrollo de ARTAZA et al. (2019), p. 154.

${ }^{45}$ ETCHEBERRY (2004), p. 128; GARRIDO (2007), p. 460. Una posición contraria o favorable a este principio puede verse en POLITOFF et al. (2006), p. 461; CURY (2005),p. 671.
} 
Conforme al Diccionario de la RAE el juzgamiento o acción de juzgar es lo dicho de un juez o un tribunal, y consiste en determinar si el comportamiento de alguien es contrario a la ley, y sentenciar lo procedente.

El juzgamiento se materializa finalmente en la sentencia, pero ella es la consecuencia del razonamiento - jurídico - seguido por el juez para la solución del conflicto sometido a su decisión. En ese sentido, como acción, es constitutiva de una operación lógica y de la denominada argumentación que es la expresión lingúistica de tal operación. ${ }^{46} \mathrm{El}$ razonamiento jurídico no es una cuestión automática y abstracta, basada puramente en lo normativo (fuente formal), sino también en otras variables que interactuan con aquello, como son las influencias informales, ideología o creencias personales, de las que hablaremos más adelante.

La operación lógica es parte del razonamiento, y como proceso mental, siguiendo a Klug, es parte de una concepción de lógica general como "teoría de la consecuencia lógica", lo que permite distinguir entre argumentos válidos y no válidos desde el punto de vista lógicoformal (lógica deductiva). Entonces, la lógica jurídica, a grandes rasgos, sería una parte especial de esa lógica general, o sea, "la teoría de las reglas lógico-formales que llegan a emplearse en la aplicación del Derecho". ${ }^{4}$

La argumentación jurídica, por otro lado, es la aplicación de las normas jurídicas a la resolución de casos, bien sea esta una actividad que llevan a cabo jueces en sentido estricto. Aquí, a su vez, cabría distinguir entre argumentaciones en relación con problemas concernientes a los hechos, o bien al derecho (estos últimos, en sentido amplio, podrían llamarse problemas de interpretación). Puede decirse que la teoría de la argumentación jurídica dominante se centra en las cuestiones - los casos difíciles - relativas a la interpretación del derecho y que se plantean en los órganos superiores de la administración de justicia. Ahora bien, la mayor parte de los problemas sobre los que tienen que conocer y decidir tanto los tribunales como los órganos no jurisdiccionales de la Administración son más bien problemas concernientes a los hechos, de manera que los argumentos que tienen lugar con ocasión de los mismos caen fuera del campo de estudio de las teorías usuales de la argumentación jurídica. ${ }^{48}$

A nivel nacional no existen teorizaciones sobre la labor de juzgamiento, sino que su mirada viene desde la literatura penal y/o criminológica comparada, donde esta actividad ha ocupado un espacio importante en el quehacer de los investigadores. En el mundo del common law es donde los estudios sobre esta temática han proliferado, desde a lo menos la década del setenta. ${ }^{49}$ Estos trabajos se han enfocado en el estudio y las críticas de lo que se conoce como prácticas de sentencing, ${ }^{50} \mathrm{y}$ han buscado entender el proceso de juzgamiento que realizan los jueces, encontrando entre otros resultados, que las sentencias y sus potenciales disparidades - contradicciones incluso-, están fuertemente relacionadas con la filosofía penal, es decir,

\footnotetext{
${ }^{46}$ ATIENZA (2006), pp. 38 y ss.

47 ATIENZA (2005), p. 27.

${ }^{48}$ ATIENZA (2005), p. 2.

${ }^{49}$ PFAFF (2005), pp. 235-307.

${ }^{50}$ VON HIRSCH y ASHWORTH (2014), pp. 696-729.
} 


\section{Polít. Crim. Vol. 16, № 31 (Julio 2021), Art. 2, pp. 30-61 [http://politcrim.com/wp-content/uploads/2021/04/Vol16N31A2.pdf]}

las preferencias penológicas y las actitudes de los adjudicadores.$^{51}$ Esta filosofía penal se ha denominado por algunos "influencias informales" 52 del proceso de juzgamiento, que se diferencian de las "fuentes formales". ${ }^{53}$ Las primeras, de cierto modo, vendrían a condicionar la decisión de juzgamiento a través de factores que se pueden denominar extralegales que representan la visión del juzgador derivada de su experiencia en ese rol, a sus propias creencias y construcciones sobre la dogmática penal y de la realidad criminal, unida a la existencia de ciertas características sociodemográficas. A su vez, las "formales" estarían compuestas por la legislación, las "guías de sentencias" (guidelines) y las decisiones judiciales, es decir, el enfoque positivo propiamente tal. ${ }^{54}$

Como ha quedado en evidencia, este tipo de distinciones dan cuenta que la labor de juzgamiento y sus resultados no son solo producto de la aplicación de reglas legales ni pueden explicarse únicamente por causas o factores en dicha línea, sino que también son producto de filosofías preconcebidas y actitudes que de cierta forma predisponen a los jueces encargados de la labor de juzgamiento y los hacen responder a los distintos casos a los cuales se ven enfrentados en base a sus creencias personales ${ }^{55}$ Esto es lo que el profesor de Derecho de Harvard y fundador de los Critical Legal Studies, Duncan Kennedy, ha calificado de "ideología", reflexionando acerca de la manera en que ella influencia los fallos de los jueces.

A diferencia de las tradicionales teorías jurídicas, Kennedy considera que las normas no son guías, sino restricciones para resolver casos. Los jueces, en consecuencia, al adaptar la norma a un caso concreto deben interpretarla. Pero en el acto interpretativo la ideología se inmiscuye. ${ }^{56}$

Para terminar este apartado, hay que realizar la observación que estos enfoques sobre la labor del juzgamiento no son los únicos, y el objetivo de este trabajo desborda una explicación más acabada. ${ }^{57}$

\subsection{Aproximaciones empíricas}

La literatura comparada evidencia diversas investigaciones, tanto con metodologías cuantitativas como cualitativas y también mixtas, que han buscado descubrir cómo operan las influencias informales en el proceso de juzgamiento. Estos estudios se han ocupado, en general, de las siguientes temáticas: a) estratificación social e inequidad en el juzgamiento; b) ejercicio de la discreción judicial y el proceso de toma de decisiones por parte de los jueces; c) la realidad práctica del juzgamiento y su contraste con los objetivos político-

\footnotetext{
${ }^{51}$ HOGARTH (1971), p. 68 y ss; MACKENZIE (2005), p. 89 y ss; DE CASTRO et al. (2019), pp. 174 y ss.

${ }^{52}$ ASHWORTH (2010), p. 41.

${ }^{53}$ ASHWORTH (2010), p. 24.

${ }^{54}$ ASHWORTH (2010), pp. 43-44.

${ }^{55}$ HOGARTH (1971), pp. 68 y ss; MACKENZIE (2005), pp. 89 y ss; DE CASTRO et al. (2019), pp.174-175.

${ }^{56}$ KENNEDY (2004), pp. 9-144.

${ }^{57}$ A modo de ejemplo, Posner reconoce la existencia de nueve teorías explicativas desde la lógica descriptiva (que se opone a las normativas): actitudinal, la estratégica, la sociológica, la psicológica, la económica, la organizacional, la pragmática, la fenomenológica, la legalista, y la propia de su autoría, la teoría de la decisión. POSNER (2011), p. 31.
} 
criminales y la regulación; y d) la influencia y adaptación a las realidades locales y contextos sociales. ${ }^{58}$

Para el primer grupo de estudios, investigaciones en base a una metodología que la podríamos tildar de heterogénea, consistente en general, en la utilización de viñetas o ejercicio de juzgamiento de casos simulados y la recolección de datos estadísticos, ${ }^{59}$ han encontrado efectos significativos de género, raza, edad y origen social en las decisiones de sentencia hecho por jueces de tribunales estatales y locales. Los delincuentes más jóvenes, delincuentes masculinos, delincuentes no blancos y de barrios menos acomodados serían más propensos a ser declarado culpable de su delito y recibir mayores penas que sus respectivos homólogos infractores. ${ }^{60}$

El segundo grupo de investigaciones analiza la sentencia como una práctica cultural. Ella está referida a los conjuntos de significados compartidos o representaciones colectivas sobre algo. Estudiar cultura es examinar las formas en que los significados son definidos, promulgados, mediados, comunicados y compartidos por una variedad de actores y audiencias. Un análisis cultural de la sentencia es un estudio de cómo los jueces se representan ciertos significados importantes. Estos incluyen representaciones de límites morales, de justicia y de procesos legítimos de toma de decisiones. El hallazgo más importante es que los jueces responden a una "cultura judicial" que es distinta y obedece al propio papel que desempeñan. ${ }^{61}$ A propósito de esto, David Garland argumenta que las instituciones penales tienen importantes dimensiones culturales y consecuencias que dan forma a las políticas y prácticas penales. ${ }^{62}$

A su vez, el tercer grupo de investigaciones, siguiendo por un lado una metodología cualitativa, ha señalado que la sentencia no es un acto neutral o mecánico, sino un proceso humano, altamente cargado afectiva y motivacionalmente. Las decisiones de sentencia tienen lugar en un entorno social de leyes, hechos, ideas y personas. Estas investigaciones se han ocupado del estudio de los procesos mentales involucrados en la toma de decisiones. Cubriendo una serie diversa de factores, tales como: problemas de sentencia (particularmente disparidades existentes); antecedentes sociales y económicos de los jueces y sus diversas filosofías penales; la naturaleza y la medición de las actitudes judiciales hacia la delincuencia; etc. Estos estudios han concluido, entre otras cosas, que existe una correlación muy alta entre la definición de situación de un juez y la sentencia que él —o ella — impone, y que si bien las sentencias impuestas por una violación particular de la ley, en circunstancias similares, pueden diferir entre los jueces, los jueces son altamente consistentes dentro de sí mismos. ${ }^{63}$

Por su parte, el cuarto grupo de investigaciones analiza las prácticas de sentencia de los jueces. Saber cómo lo jueces manejan los casos que conocen y determinar en concreto por

\footnotetext{
${ }^{58}$ ULMER (2012), p. 2.

${ }^{59}$ SPOHN (2009), pp. 82-83.

${ }^{60}$ MILLER (2015), pp. 1-57.

${ }^{61}$ HUTTON (2006), pp. 155-174.

${ }^{62}$ GARLAND (1999), p. 230.

${ }^{63}$ HOGARTH (1971), p. 18; Estudios similares. MACKENZIE (2005); MAGUIRE (2014), pp. 62-72; JOHNSON (2014), pp. 696-729.
} 


\section{Polít. Crim. Vol. 16, № 31 (Julio 2021), Art. 2, pp. 30-61 [http://politcrim.com/wp-content/uploads/2021/04/Vol16N31A2.pdf]}

qué y en qué casos los jueces deciden que una pena privativa de libertad es apropiada. Se busca comprender cómo los jueces ejercen su papel de hacedores de justicia. Estudios en esta línea han confirmado la percepción de que los jueces tienen estilos de sentencia distintos, una perogrullada, pero basados en factores estructurales legales y no legales que explican parcialmente esas diferencias. Las prácticas de los jueces están moldeadas por las realidades locales distintivas en las que practican el juzgamiento. Las diferencias sociales, económicas y geográficas afectarían la toma de decisiones de los jueces. ${ }^{64}$

En Chile el proceso de juzgamiento de los jueces no ha sido un tópico muy estudiado y, menos aún, a propósito de los concursos. Sin embargo, han existido algunas investigaciones en materia penal que son importantes de destacar, sobre todo por las metodologías que han utilizado y porque abordan particularmente el proceso de determinación de la pena en términos generales.

El primer estudio que interesa revelar es el de la Fundación Paz Ciudadana, ejecutado el año 2001, sobre la base de la revisión de 2.990 sentencias condenatorias, pronunciadas el año 1997 por tribunales con competencia penal, en diversas zonas geográficas de nuestro país y que buscaba establecer el proceso de determinación de la pena. El estudio permitió establecer empíricamente que los jueces tienden a fijar la pena en el punto mínimo del marco penal. ${ }^{65}$

En la misma senda y con resultados similares, pero más amplio en la explicación, destaca el estudio Wilenmann y otros publicado recientemente, el que en base a evidencia disponible y otra producida a partir de la revisión de 1000 sentencias condenatorias pronunciadas exclusivamente por tribunales orales en lo penal de capitales de provincia durante el año 2016, perseguía establecer el proceso de determinación de la pena en lo relativo a la identificación de la naturaleza de la sanción y la individualización de la misma en cuanto a su cuantía o duración como asimismo analizó las consecuencias y defectos de esa configuración. ${ }^{66}$

Otro estudio, sin que ello implique un agotamiento de todos los existentes, pues va más allá del propósito de esta investigación, es el de Droppelman y otros, los que mediante una metodología consistente en una encuesta factorial aplicada a 202 jueces, sean de garantía o de tribunales orales en lo penal, buscaba determinar los factores que influyen en el juzgamiento juvenil. El análisis dio cuenta que, si bien los factores legales son decisivos sobre la toma de decisiones judiciales, este proceso no se basa en ellos de forma exclusiva. Ciertos factores extralegales también podrían explicar de mejor manera la decisión de dictar una sanción privativa de libertad por parte de ellos. ${ }^{67}$ Quizás este sea el único estudio conocido, que es pionero e intenta explorar en las causas o factores extralegales en la actividad de juzgamiento penal.

Al estudio anterior, se suma otro que manifiestamente quiere abordar este objetivo del sentencing. Se trata del trabajo de Morales y Salinero, el que, en base a una metodología de

\footnotetext{
${ }^{64}$ VELASQUEZ (2018), p. 253.

${ }^{65}$ HURTADO y JÜNEMANN (2001), p. 11.

${ }^{66}$ WILENMANN et al. (2019), pp. 456-490.

${ }^{67}$ DROPPELMAN et al. (2017), pp. 129 y ss.
} 
tipo cualitativa, donde la recolección de la información se basó en la práctica de entrevistas semiestructuradas a diversos jueces (muestra de 22 jueces), buscó en general conocer el proceso de juzgamiento y control de la ejecución de las penas sustitutivas. Siendo sus objetivos específicos: a) Conocer las preferencias penológicas de los jueces y su influencia en el proceso de juzgamiento de las penas sustitutivas; b) Comprender el proceso de decisión y motivación (o su ausencia) de las penas sustitutivas; y finalmente c) Indagar acerca de la labor de control de la ejecución de las penas sustitutivas. ${ }^{68}$

\section{Objetivos y metodología}

Como se dijo en la introducción, el objetivo general de este trabajo es conocer el proceso de juzgamiento o sentencing de los concursos de delitos por parte de los jueces. Sus objetivos específicos son: a) Comprender el proceso de decisión y motivación para cuestiones concursales, y saber si existen fuentes informales determinantes en ese proceso; b) Conocer e identificar las cuestiones observadas por los jueces para determinar una unidad o pluralidad delictiva, y c) Deteminar la complejidad que presentan los concursos en la labor de juzgamiento.

El método utilizado en esta investigación es de tipo cualitativo mixto, en el cual la técnica de recolección de la información se basó en la solución de casos simulados, particularmente cuatro casos, cuyos supuestos fácticos se reproducen en el presente estudio, y tienen las características de evidenciar un problema de unidad o pluralidad delictiva, también de afectar bienes jurídicos distintos y de diversa entidad ${ }^{69} \mathrm{~A}$ lo anterior, se suma algunas entrevistas de carácter semi-estructuradas que se realizaron a esos jueces con el objeto de llenar ciertos aspectos que la metodología anterior no pudo absolver.

En total, se entrevistó a una muestra de doce jueces $(\mathrm{N}=12)$, todos de la Región Metropolitana, integrada en $83 \%$ por jueces de tribunales orales y $17 \%$ por jueces de garantía. El trabajo de terreno fue realizado entre los meses de mayo y diciembre de 2019, mediante una sesión de solución de casos y entrevistas personales respectivamente. La participación de casos fue en razón de 10 jueces en algunos (casos 1 y 2) y 5 en los otros (casos 3 y 4). El proceso de selección de los jueces no fue aleatorio, sino que obedeció a razones de afinidad con algunos de ellos y también, en base a la técnica bola de nieve, alguno de los jueces podía presentar a otro sentenciador que quisiera participar en el estudio y así sucesivamente.

Además, esta investigación contó con las autorizaciones del Comité de Ética de la Universidad de Talca. La individualización de cada uno de los jueces participantes en el ejercicio de solución de casos y entrevistados quedó definida bajo estrictos criterios de confidencialidad, por tanto, no se presentan en esta investigación los nombres específicos de aquellos, ni información del tribunal al que pertenecían.

La información fue procesada a través del software Nvivo 12.

\footnotetext{
${ }^{68}$ MORALES y SALINERO (2020), pp. 319-341.

${ }^{69}$ Los casos fueron creados por el autor de este estudio, validados por el Dr. Francisco Maldonado Fuentes, y obedecen a casos que podríamos denominar complejos, no por ello atípicos en cuanto a su existencia, pues refelajn un problema de unidad y/o pluralidad delictiva.
} 


\section{Resultados}

En este apartado se expone la percepción de los jueces recogidas mediante dos técnicas complementarias, como son la resolución de casos simulados y las entrevistas de carácter semi-estructuradas.

Para una mejor exposición de los hallazgos, a continuación se exhibe cada caso simulado, dividiéndolos por el nombre del mismo ("Violación", "Homicidio", "Robo" y "Bomba") y separando estos, a su vez, entre aquellos sentenciadores que determinaron una unidad o una pluralidad delictiva, para terminar identificando si la fuente de información se obtiene desde el propio ejercicio de simulación o de la entrevista.

Se hace la salvedad que en la exposición de los resultados no se dará respuesta a la preguntas que son los objetivos del trabajo, sino que se presentarán simplemente los resultados, sin ningún agregado, salvo la separación antes explicada, para luego, en la discusión responder a partir de la información recolectada las tres finalidades preliminarmente planteadas.

\subsection{Caso "Violación"}

"Tristán es un joven de 25 años que sigue por algunas cuadras a Mabel, mujer de 20 años, quien viene saliendo de su trabajo un día de verano a eso de las $20 \mathrm{hrs}$. Mientras Mabel caminaba tranquilamente, Tristán la aborda, tomándolo del cuello y la cintura, y la introduce mediante fuerza en una casa con su puerta entreabierta que había en el sector por donde ambos transitaban. Casa que tenía claros signos de estar desocupada. Ya en el interior, mientras la mujer hacía alardes de gritar pidiendo auxilio, el hombre coloca una media en la boca y ata sus manos con unas esposas que traía consigo. La tira sobre una colchoneta y procede a subirle las faldas y quitarle las bragas que llevaba, para posteriormente practicarle sexo oral (consistente solo en la frotación de su lengua con la parte externa de la cavidad vaginal) y de manera coetánea flotaba los pechos de la mujer, cosa que hace por aproximadamente 5 minutos. Luego de ello, y un tanto frustrado por no logra lubricar el sexo de la mujer, decide introducir en la cavidad un consolador que también llevaba consigo, con el cual la penetra en reiteradas ocasiones por la vagina. Una vez transcurridos uno 20 minutos y la muchacha un tanto desmayada por la situación y el trauma vivenciado, Tristan se va a una botillería del sector para comprar y tomarse dos botellas pequeñas (petacas) de Ron, cosa que hace por el transcurso de 1 hora, tras lo cual vuelve a la casa y procede a penetrar con su miembro viril la cavidad vaginal y anal de Mabel por el lapso de unos 15 minutos. Finalmente decide arrancar del lugar".

En esta simulación, la mayoría de los juzgadores concibe la concurrencia de una pluralidad de delitos, en cambio la minoría advierte un solo tipo penal. Sin perjuicio de esto, la unanimidad de los adjudicadores reconoce la presencia del delito de violación según revela el ejercicio de simulación. 
a) Unidad de delito

Los sentenciadores en su minoría, 3 de 10 jueces, estimaron que es el delito de violación la única descripción típica que concurría en el enunciado fáctico de la simulación.

$\mathrm{Al}$ indagar por las razones de esta unidad delictiva, se presenta el contexto situacional como la respuesta predominante.

"Existe un delito de violación porque todo el hecho se enmarca en un solo contexto espaciotemporal..... Todo lo demás resulta irrelevante porque están dentro la misma situación típica" (Juez Oral).

Para legitimar la respuesta, se recurre a argumentos que podrían ser considerados como una falacia por autoridad, pero que son reconocidos por nuestra legislación en el deber de la fundamentación de la sentencia, como son las denominadas "máximas de la experiencia". En ese sentido, es la experiencia la que permite a los juzgadores, de manera automática, arribar a un juicio de adecuación típica.

"La calificación quizás uno lo hace más automático...esta viene dada por la experiencia que es la que permite ver lo que estoy viendo...me refiero a la experiencia en la actividad jurisdiccional que permite la calificación jurídica. Quizás una persona recién iniciada no lo pueda hacer de manera tan rápida. Uno tiene de base ciertos parámetros que te prejuzgan un poco" (Juez Oral).

Estos jueces que declararon en el ejercicio de simulación que el supuesto fáctico solo se correspondía con el delito de violación, a fin de cuentas, también reconocieron la concurrencia de otro delito pese a afirmar solo uno. De esta línea, 2 de 3 jueces indicaron que ese delito que, además se presentaba, era el abuso sexual. Ellos manifestaron que el abuso desaparecía por existir un concurso medial entre ese delito y la violación, y en el proceso de subsunción el primero era absorbido por la violación porque operaba dentro de un contexto de medio a fin (tocaciones con propósito de lubricar a la mujer). El tercer adjudicador que solo reconocía una violación no se representó un abuso sexual, sino solo un delito de secuestro, pero este fue eliminado de su proceso de sentenciamiento, también por subsunción, por la escasa relevancia temporal de la afectación a la libertad, la que además estaba dirigida o encaminada afectar la libertad sexual — no la ambulatoria-.

En las entrevistas, al profundizar cómo opera la susbsunción se relata que esta consiste en el predominio del delito más grave.

"Yo tengo que subsumir todos los delitos concurrentes en el delito más grave" (Juez Oral)

Por su parte, al requerir información si se necesitaba algún conocimiento especial para ese proceso de subsunción, se aludió a la necesidad de contar con conociemientos en la disciplina penal. 


\section{Polít. Crim. Vol. 16, № 31 (Julio 2021), Art. 2, pp. 30-61 [http://politcrim.com/wp-content/uploads/2021/04/Vol16N31A2.pdf]}

"Si no tengo el conocimiento técnico que viene dado por la dogmática no puedo hacer el ejercicio de subsunción..." (Juez Oral).

\section{b) Pluralidad de delitos}

Según las simulaciones, los que consideran la convergencia de una pluralidad de delitos, 6 de 10 jueces, reconocen además de la violación la concurrencia de los delitos de abuso sexual y del abuso sexual agravado respectivamente. A su vez, 2 de 10 señalaron que además de estos delitos, concurrían también los delitos de secuestro y de violación de morada.

En los ejercicios se detecta que las soluciones para la existencia de una pluralidad de delitos, si bien son concursales, ellas son del todo heterogéneas. Algunos indican la presencia de un concurso ideal (1), otros la presencia de un concurso real pero resuelto como delito continuado (2), y otros que estamos frente a un concurso aparente de leyes penales (4).

Las entrevistas colaboraron en poder determinar cuáles son las cuestiones observadas por los adjudicadores para saber si estamos en presencia de un concurso de delitos. En ese sentido, destaco una concepción cuantitativa para afirmar la presencia de un concurso, esto es, estar en presencia de dos o mas delitos, de una pluralidad de normas jurídicas, tratarse de varias víctimas e intereses jurídicos involucrados.

"Las condicionantes para saber si estamos en presencia de un concurso son la pluralidad de delitos, la pluralidad de normas aplicables, la pluralidad de víctimas, también bienes jurídicos distintos..." (Juez Oral).

También en la misma línea anterior de saber qué se observa para determinar o descartar el concurso, pero desde la óptica de la individualización de un proceso, secuencia u orden consecutivo de cuestiones que se tienen presentes en el desarrollo mental del juez, destaca que se parte por el hecho del mundo real, luego por el tipo penal y finalmente las normas concursales concurrentes.

"Uno mira el hecho que sucedió y está pensando en la parte especial del Derecho, una vez definida la situación concursal, mira las normas de los arts. 74, 75 y 351” (Juez Oral).

Al explorarse en los ejercicios de simulaciones los argumentos vertidos por los adjudicadores para determinar la naturaleza del concurso concurrente, estos presentan algunas similitudes fácticas.

El sentenciador que defiende el concurso ideal consideró en el ejercicio que hay una unidad jurídica pues los tipos penales concurrentes se presentan en un mismo contexto temporal, donde prevalece la violación que absorbe a los demás delitos.

A su vez, los que sostienen un concurso real (2 jueces), reconocen la existencia de diversos hechos asociados a cada delito por evidenciarse en ellos a los mismos participantes (victimario y víctima), un mismo espacio temporal, la afectación de un mismo bien jurídico, por lo que consideran que hay un delito continuado. La diferencia entre ambos adjudicadores 
viene dada porque uno condena por delito de violación y señala que en los diversos hechos existe un mismo dolo como exigencia para la calificación de un delito continuado y, el otro sentenciador, considera un delito de secuestro calificado.

La tercera solución, estaba dada por los que consideraron un concurso aparente, señalando es sus simulaciones que hay una unidad de acción y consunción de los delitos de menor entidad con respecto a la violación — el de mayor gravedad —. También se indica que se comete el delito en un solo espacio, se trata de un acto continuo, a una sola víctima, donde el medio consistente en la fuerza no se puede escindir para configurar dos delitos. La violación contiene el abuso sexual que lo antecede. Además se indica que no existe una especial vulneración del bien jurídico, más allá del protegido por la violación. En ese sentido, se indica que el marco penal de este último delito permite recoger las especiales particularidades del hecho. Se afirma el concurso aparente porque los diversos delitos concurrentes afectan el mismo bien jurídico. La dinámica de los hechos, le existencia de una sola víctima, y la penalidad de la violación abarca el resto de los injustos. El abuso sexual agravado también importa una afectación a la libertad sexual, absorbido por la violación, que implica solo un aumento del daño.

Pese a la heterogeneidad de posiciones, los diversos adjudicadores, en una proporción de 9 de 10, llegan a condenar por un solo delito, el de violación, y el adjudicador restante condena por un delito de secuestro con violación.

\subsection{Caso "Homicidio"}

"Mientras Juan, Manuel y Luis se encuentran en una reunión discutiendo sobre los diversos aspectos de la sociedad comercial que conforman los tres. Luis (gerente de la compañía), es increpado por Manuel, debido al manejo poco cuidadoso y profesional en la dirección de los negocios, el que ha traído como consecuencia la pérdida de diversas licitaciones que implican negocios futuros no adjudicados. Las elocuciones sobre la administración de Luis son fuertes (no mal educados), pero con un tono sarcástico que hacen que el afectado se ofusque y decida retirarse intempestivamente de la cita. Ya en el exterior, Luis al ver que sale Manuel de la empresa, decide tomar la camioneta de Juan, quien acostumbra a dejar las llaves al volante, se trataba de una hermosa Ford 350, del año, avaluada en el mercado automotriz en más de M\$30, enciende el motor y como un enajenado pone en marcha la maquina y enviste a alta velocidad a Manuel, causándole inmediatamente la muerte por diversos traumas mortales. A raíz del choque, la camioneta de Juan queda con daños menores, avaluados en \$100 mil pesos"

En esta simulación, 5 de 10 jueces (la mitad) reconocen en el supuesto fáctico solo un delito de homicidio y de daños; 3 de 10 reconocen, además de los delitos anteriormente señalados, la concurrencia de un hurto; 1 declara además la concurrencia de injurias; y finalmente 1 más declara la existencia de un homicidio simple.

\section{a) Unidad de delito}

En este caso, no hay jueces que reconozcan un único delito. 


\section{b) Pluralidad de delitos}

Como se dijo, la unanimidad de los sentenciadores reconocen un concurso de delitos y todos concordaron en la presencia de un ilícito de homicidio y de daños respectivamente. Las diferencias se presentan en que no solo se queda con esos delitos, sino también se declara la concurrencia de distintos tipos penales adicionalmente.

En relación con los problemas concursales, 4 de 10 jueces evidenciaron en los ejercicios un concurso real entre los tipos penales de homicidio y daños. Al indagar cuáles eran las razones para arribar a esa conclusión, los fundamentos recurrentes fueron la estructura de ambos tipos penales respecto de un mismo autor, por existir una afectación a distintos bienes jurídicos y por identificarse distintas víctimas.

Mediante la entrevista se intentó establecer cuál era el proceso mental que realizaba un juzgador para establecer en el supuesto fáctico la presencia de un delito. El encuadre del hecho real y norma abstracta, o denominado ejercicio de tipicidad, es el proceso natural.

"Para el ejercicio de saber que delitos concurren, pienso en el hecho y luego en la ley, en el delito, y veo si calza o no en cuanto a todos sus elementos" (Juez Oral).

Al investigar vía entrevistas que requisitos se exigen para determinar la existencia de un concurso real, las respuestas se orientaban en la necesidad del saber de la dogmática penal.

"Para determinar un concurso yo debo saber tanto de parte general como especial" (Juez Oral).

Igualmente, para saber qué cuestiones se deben advertir para afirmar un concurso (real), llama la atención que también hay observación de cuestiones subjetivas, como es la intención exteriorizada del sujeto activo.

"Yo veo un concurso real. Veo una intención manifiesta de cometer el delito de homicidio y de daños. Provocar la muerte o a lo menos lesionar gravemente, y causar daños al vehículo...." (Juez Oral).

Por otro lado, en relación a la concurrencia de estos delitos de homicidio y daños, un sentenciador, en el ejercicio de simulación, evidencia un concurso ideal, declarando que las razones para ello son la existencia de un solo hecho, un solo actor, la existencia de dos víctimas y dos bienes jurídicos distintos también.

En la misma simulación, 3 de 10 jueces advierten la existencia de un concurso medial, pero declaran la concurrencia de distintos tipos penales. La mayoría indica la existencia de daños para causar el homicidio. Además, los daños se ocasionan en el instrumento que es, al mismo tiempo, el medio para causar la muerte. En otro sentido, la minoría estima un concurso medial entre el hurto y el homicidio porque sin la apropiación del instrumento no se puede ocasionar la muerte constitutiva del homicidio. Solo 1 juez sostuvo la concurrencia de un concurso ideal entre el homicidio y el delito de daños, pero hace hincapié que por aplicación de la 
infracción a la prohibición de doble valoración o non bis in idem se debe condenar por el delito más grave.

En otro orden de cosas, 6 de 10 juzgadores declararon en los ejercicios advertir la presencia de un concurso aparente de leyes. Los daños son absorbidos por el homicidio en consideración a un criterio de relevancia y porque la pena de este último delito expresa el desvalor del primero; la mitad de los entrevistados entiende que los daños están subsumidos en la pena del homicidio y el instrumento matador es, al mismo tiempo, el instrumento dañado.

Cabe hacer presente que uno de los adjudicadores aduce en las entrevistas situaciones subjetivas, como la falta de antecedentes penales del actor para condenar solo por el homicidio y así justificar el desplazamiento de los daños. También se esgrimieron concepciones punitivas personales para fundar una decisión como aquella basada en la teoría de la prevención.

"No considero factores extralegales en la decisión de condena o absolución, pero podría existir en la determinación de la pena. No factores extralegales, pero si razones de prevención general o especial" (Juez Oral).

Para terminar este caso, se les preguntó a los jueces en las entrevistas si los concursos, en cuanto a su presencia y problemas, se reflejaban en la sentencia. Las respuestas fueron afirmativas en amplia mayoría porque existe una necesidad de motivar la resolución, sumado además a explicitar la regla de solución de la pena. Sin embargo, se atendía solo a fundamentar el concurso real e ideal.

"El concurso real e ideal se razonan y se fundamentan en la sentencia porque además debo determinar y especificar la regla de solución... Tengo que explica uno y el otro...." (Juez Oral).

"La identificación del concurso determina la pena, por eso la importancia” (Juez Oral)

Como se señaló, se fundamenta el concurso real e ideal en la sentencia y no así el aparente que presentaría, según los entrevistados, una operación mental automática, sumado a la complejidad de su estructura.

"No fundamento cuando estamos frente a un concurso aparente, es automático. Considero que es innecesario. Resulta evidente, pero también podría haber cierto desconocimiento" (Juez Oral).

"Reconozco que los colegas no razonan mucho sobre el concurso aparente, pero también las sentencias responden a lo que piden las partes" (Juez Oral).

Sin perjuicio de lo anterior, una minoría expusó en las entrevistas que fundamentaba el concurso aparente en las sentencias porque tenía obligación legal, pese a reconocer lo difícil del proceso. 


\section{Polít. Crim. Vol. 16, № 31 (Julio 2021), Art. 2, pp. 30-61 [http://politcrim.com/wp-content/uploads/2021/04/Vol16N31A2.pdf]}

"Fundamento el concurso aparente porque es mi deber y debo señalar porque se presenta... es complejo y a veces me cuestiono por qué hacerlo, incluso si nadie lo cuestione" (sic) (Juez Oral).

\subsection{Caso "Robo"}

"Era un día lluvioso en Santiago, a eso de las 11 am, y Eliot, conocido como el asaltante solitario, decide entrar a robar a la sucursal de Teletrack (oficina de apuesta de caballos) de Av. Apoquindo. En su interior, había solo dos cajeros y un guardia de seguridad, seguido por dos apostadores de sexo masculino quienes estudiaban en un libro como distribuirían sus apuestas en la jornada de carreras (total 5 personas). Eliot, premunido de una ametralladora, de aquellas que se veían en la época de los mafiosos de la ley seca de Chicago, la cual tenía empuñaduras de madera y una bobina cilíndrica de fierro negro que contenía las balas, la cual intimidaba elocuentemente en aspecto, entra al lugar y grita "todos los CTM con las manos arribo o los mato", mientras con el arma hacía un paneo apuntando a todos y cada uno de los presentes. Acto seguido, les indica a todos que se tiren al piso y comienza a registrar los bolsillos de cada uno de los presentes, sacando de ellos diversas especies, como: celulares; billeteras; un maletín, cuyo dueño opone resistencia, pero recibe un culatazo en su cara fracturando la mandíbula de su dueño, uno de los apostadores. Finalmente, a uno de los cajeros le sustrae el dinero previsto para comenzar la caja de la reunión hípica, el cual no pasaba de unos 100 mil pesos en diversos billetes y monedas. No está demás decir que las especies de mayor valor eran un celular HAWAI de uno de los cajeros, el cual estaba avaluados en M\$1, y el maletín del apostador golpeado que contenía M\$5.”

En este ejercicio los sentenciadores eran un número menor que los dos casos anteriores. Sin perjuicio de ello, 4 de 5 jueces advierten en los ejercicios y en las entrevistas un solo delito de robo con violencia, no obstante la multiplicidad de víctimas. Y, por otro lado, un juzgador reconoce la concurrencia de un delito de robo con intimidación con uno de robo con violencia.

\section{a) Unidad de delito}

La gran mayoría reconoce en los ejercicios un delito de robo con violencia, pues la voluntad del sujeto activo es robar, sin que pueda dividirse su conducta en correspondencia al total de personas afectadas. Se manifiesta que el dolo del robo con violencia recoge todas las demás conductas que ya están en el tipo penal, pese a la pluralidad de víctimas.

Por su parte, las entrevistas entregan información para descartar un problema concursal, toda vez que los sentenciadores identifican un solo contexto espacio temporal. En sus voces habría un concurso cuando existe una interrupción respecto de estos medios físicos como tiempo y/o lugar.

"No hay concurso porque todo ocurre en una sola situación fáctica sucesiva. Uno va derechamente a la calificación jurídica principal... Uno califica varios hechos cuando hay un corte o interrupción en el tiempo, lugar o víctima." (Juez Oral). 
Mediante las entrevistas se pidió a los juzgadores identificar los presupuestos para sostener un único delito de robo con violencia. En ese sentido, nuevamente se esgrimen argumentos ambientales, como la existencia de un mismo espacio temporal, sumado a que se trata de intereses sociales protegidos de similares características y la existencia de una intención final del autor. No obstante, también se esgrime una dinámica comisiva in crescendo, las cual en un mismo contexto pasa de una amenaza a una lesión.

"La acción para mí pasa por ingresar con el arma, amenazar y hacer efectiva la a amenaza respecto de una misma persona. Es una acción continua que se da en una inmediatez. Esta inmediatez está integrada porque es la misma persona, con la misma arma que intimida y después hiere. También están todos los sujetos en el mismo lugar. Hay un mismo tiempo. Y los bienes jurídicos son similares. Además, la intención del sujeto es todo el rato la misma. No quería violar, sino robar" (Juez Oral).

A raíz de la respuesta anterior, se buscó descubrir si la acción y hecho son custiones sinónimas, declarando ser cuestiones distintas, donde la primera parecería ser el medio para conseguir la segunda que se hace equivalente a un resultado.

"Acción y hechos son cosas distintas. El hecho es un resultado de una acción perpetrada por alguien. Por regla general una acción genera un resultado...En los delitos de mera actividad la acción se confunde con el resultado" (Juez Oral).

También es interesante que los juzgadores reconocen que un hecho puede comenzar bajo los presupuestos de una determinada tipología delictiva, pero luego se transforma en otra mediante un examen de resultado o por la visión de conjunto.

"Parte como robo con intimidación, pero luego se convierte en un robo con violencia por la fractura.... Más que un concurso podemos identificar varias figuras típicas, pero yo la califico como solo un delito de robo con violencia....'(Juez Oral).

La cantidad de víctimas si bien no es una variable que en este caso permite a los jueces comprender una multiplicidad de tipos penales concurrentes (concurso real homogéneo). Si es una varible que incide en la determinación de la pena por la mayor extensión del mal causado por el delito como revelaron las entrevistas.

"Condenaría por el robo con violencia pero no en el mínimo, porque hay múltiples resultados y debo fundamentar que la acción afectó a varias personas" (Juez Oral).

\section{b) Pluralidad de delitos}

Solo un sentenciador en los ejercicios consideró la presencia de un concurso, el que sería de naturaleza medial, y vendría dado porque el robo con intimidación constituiría el medio para cometer el robo con violencia.

Al investigar en las entrevistas cuál era la razón o fundamento que servía para afirmar el concurso medial, se señaló que se parte con las amenzazas propias del robo con intimidación, 


\section{Polít. Crim. Vol. 16, № 31 (Julio 2021), Art. 2, pp. 30-61 [http://politcrim.com/wp-content/uploads/2021/04/Vol16N31A2.pdf]}

las que posteriormente se transforman en una concreta lesión de la integridad física de la víctima. Igualmente se indica que el tipo penal que prevalece lo hace en base a un criterio de gravedad, esto es, la afectación a la salud es más grave que simple amaneaza a ella.

"Comienza como un robo con intimidación pero se transforma en uno con violencia. El robo con violencia se come a la intimidación porque es un acto más grave pese a que tienen igual pena, pero es más grave porque pasas del riesgo de la afectación a la indemnidad física al hecho puro de agredir a una persona...... la amenaza se transforma en el resultado. Y el bien jurídico comprometido en este delito es más importante, es la integridad de la persona... Para mi es un concurso medial, pues parto con la amenaza que es el medio, pero término con un resultado distinto" (Juez Oral)

\subsection{Caso "Bomba"}

"Ricardo no es un anti sistémico y tampoco pertenece a ninguna organización o movimiento político o social. Su hobby es la construcción de aparatos explosivos. Un día, ya cansado de no probar el efecto destructivo de las bombas que confecciona, decide probar una de ellas, para lo cual ingresa a una iglesia de Santiago, y en una capilla aledaña y pequeña, en la que se encontraban unas 10 personas de distinto sexo y edad, instala el aparato, el cual hace estallar transcurrido un minuto desde que egresa, mediante una activación motora a distancia. Producto de la explosión, mueren las 10 personas, dentro de las cuales no había un clérigo. Tampoco está demás decir que Ricardo una vez que ingreso al lugar, vio la capilla y la gente circundante en ella, sabía que el poder de fuego del artefacto era suficiente para matar a todos los presentes".

Para este caso, las simulaciones mostraron que la totalidad de los jueces considera la presencia del delito de homicidio. La diferencia en este ejercicio viene dada por el número de delitos concurrentes, donde la mayoría, esto es, 4 de 5 jueces considera la presencia de un solo delito de homicidio con multiplicidad de víctimas y, a la inversa, la minoría entiende concurrente tantos delitos como muertes existen.

\section{a) Unidad de delito}

En las simulaciones, el fundamento de la mayoría es que se está frente a un único delito porque hay un solo hecho y la acción matadora también es una sola, aunque con resultado múltiple. Agregan que se está frente a un concurso ideal. En esa misma línea, las entrevistan reafirmaron esa idea de concurso y la necesaria diferencia que un hecho puede tener diversas acciones.

"Hay un concurso ideal... Un mismo hecho con pluralidad de víctimas..." (Juez Oral).

"Hay solo un homicidio. Hay un solo hecho, lo cual no es sinónimo de acción, pues el hecho puede tener diversas acciones...El hecho es el contexto de la situación fáctica concreta..."(Juez Oral). 
Interrogados los sentenciadores para saber si estamos ante un problema concursal. Se vuelve a la clásica discusión de determinar cuantitativamente si hay un delito o varios de ellos. Lo interesante es que para determinar la presencia de un delito se acude a conocer su estructura típica, lo que demanda un conocimiento técnico de los delitos en particular y en general, y de esa manera conocer la extensión de cada uno de ellos.

"Los concursos se construyen desde la parte especial y la parte general, pues necesito saber cuándo estoy en presencia de un delito y de una pluralidad de delitos, pero también necesito saber como se configura un delito en cuanto a sus elementos típicos... porque si no lo sé no puedo saber cuando empieza y acaba un delito..."(Juez Oral).

\section{b) Pluralidad de delitos}

Solo un sentenciador declaró en la simulación la presencia de una pluralidad de delitos. Lo hizo porque entendió la cantidad de delitos conforme la cantidad de resultados.

Al indagar en la entrevista el tipo de concurso se estableció que este era de naturaleza real. No obstante aquello, es interesante saber que la razón para esa resolución se encuentra en el plano subjetivo del sujeto activo, pues este sabía de manera previa a la ejecución el resultado múltiple de la misma.

"Hay 10 homicidios por que hay 10 muertes y el sujeto sabía que iban a ser 10. Independiente que el artefacto era uno solo porque el poder del aparato el lo sabía...Hay un concurso real" (Juez Oral).

Finalmente, cabe resaltar que en las simulaciones también se reflexiona sobre aspectos del tipo subjetivo como determinar si el homicidio se cometió con dolo directo o eventual, como de si de ello dependiese la existencia o calificación de la tipología concursal.

\subsection{Corolario de los casos simulados}

De lo anteriormente expuesto a propósito de los casos simulados, no es difícil advertir que las miradas de los adjudicadores en torno al concurso (real, idea, medial, y aparente), fue disímil. Nunca se encontró una unanimidad de criterio respecto al concurso que se presentaba en cada ejercicio, y tampoco existió coincidencia en los casos en que los adjudicadores negaban la existencia de un problema concursal, pues las justificaciones también eran distintas.

Para facilitar la corroboración de la aseveración anterior, a continuación se describe una tabla (Tabla 1) en donde se expone en primer lugar la respuesta esperada para cada caso ${ }^{70}$, para luego proceder a marcar en término de $n^{\circ}(X)$ aquellos jueces que marcaron la concurrencia de un determinado concurso, que en algunos de los cuatro casos puede ser más de uno, y luego en una columna denominada "Cercanos a la solución" indicar la repuesta entregada,

\footnotetext{
${ }^{70}$ Para establecer la situación concursal concurrente, se le solicitó al Dr. Francisco Maldonado que desarrollara una propuesta de solución. Que sea a él a quien se le pide la resolución de casos obedece a varias circunstancias, pero particularmente a que este trabajo se enmarca en el proyecto Fondecyt que él dirige.
} 
en carácter binario, cuando el $51 \%$ o más de los jueces concordó con la solución propuesta, señalándolo con la expresión "Sí" y, en cambio, con el término "No" cuando un número menor al 50\% de los jueces no llega a esa solución.

Tabla 1.

\begin{tabular}{|c|c|c|c|c|c|c|c|}
\hline $\begin{array}{l}\text { Nombre } \\
\text { del caso }\end{array}$ & $\begin{array}{l}\text { Solución concursal } \\
\text { esperada }\end{array}$ & $\begin{array}{c}\text { Concurso } \\
\text { Real }\end{array}$ & $\begin{array}{l}\text { Concurso } \\
\text { Ideal }\end{array}$ & $\begin{array}{c}\text { Concurso } \\
\text { Medial }\end{array}$ & $\begin{array}{l}\text { Concurso } \\
\text { Aparente }\end{array}$ & $\begin{array}{l}\text { No hay } \\
\text { concurso }\end{array}$ & $\begin{array}{l}\text { Cercanos } \\
\text { a la } \\
\text { solución }\end{array}$ \\
\hline Violación & $\begin{array}{c}\text { Concurso aparente de } \\
\text { leyes entre la violación } \\
\text { que absorbe el abuso } \\
\text { sexual (regularidad)); } \\
\text { Concurso ideal entre los } \\
\text { delitos sobrantes } \\
\text { violación y abuso sexual } \\
\text { agravado. }\end{array}$ & $\mathrm{XX}$ & $X$ & XX & XXXX & XXX & No \\
\hline $\begin{array}{l}\text { Homicidio } \\
\text { Calificado } \\
\end{array}$ & $\begin{array}{c}\text { Concurso ideal de } \\
\text { delitos (regularidad) } \\
\text { entre todos los } \\
\text { concurrentes y se } \\
\text { sanciona por el } \\
\text { homicidio calificado. }\end{array}$ & $\mathrm{XXXX}$ & $X$ & $\mathrm{XXX}$ & $\begin{array}{c}\mathrm{XXXXX} \\
\mathrm{X} \\
\end{array}$ & & No \\
\hline Robo & $\begin{array}{l}\text { Hay concurso ideal } \\
\text { entre el robo con } \\
\text { violencia y robo con } \\
\text { intimidación se solapan } \\
\text { en sus propiedades } \\
\text { coactivas de manera de } \\
\text { no poder valorarse dos } \\
\text { veces (regularidad); } \\
\text { sucede lo mismo con las } \\
\text { lesiones respecto del } \\
\text { robo calificado; y lo } \\
\text { mismo se repite entre el } \\
\text { robo con violencia y el } \\
\text { califificado. }\end{array}$ & & $X$ & & & XXXX & No \\
\hline Bomba & $\begin{array}{l}\text { Concurso ideal respecto } \\
\text { de diez delitos de } \\
\text { homicidio }\end{array}$ & X & XXXX & & & & Sí \\
\hline
\end{tabular}

Fuente: Creación propia con las respuestas obtenidas en la simulaciones.

Como se advierte de la tabla anterior, la afirmación de que no se encontró una unanimidad de criterio respecto al concurso que se presentaba en cada caso encuentra correlato empírico. Frente a un idéntico caso existen soluciones concursales diversas. Soluciones que incluso escapan a las que presenta la doctrina antes revisada para esos mismos casos o parangonables.

\section{Discusión y conclusiones}

En esta parte final del trabajo, serán sometido a escrutinio los resultados del estudio mediante la discusión y análisis de cada uno de los objetivos específicos que fueron planteados. 
a) Comprender el proceso de decisión y motivación para cuestiones concursales, y saber si existen fuentes informales determinantes en ese proceso

Lo primero que los juzgadores vislumbran antes de plantearse una cuestión de unidad o pluralidad delictiva es el hecho ocurrido en el mundo real y determinar cómo él se relaciona con un tipo penal. El clásico ejercicio de tipicidad pasa por establecer si la situación acontecida en la realidad calza con la descripción legal, en el sentido de encontrar en ella representados los diversos elementos que componen el tipo penal. De manera que, si se afirma tal situación, pasa el primer tamiz valorativo previo a la antijuridicidad y culpabilidad para constatar la existencia de un delito. ${ }^{71}$

Ese análisis comparativo entre la realidad y norma legal, como explicaban los jueces, se construye a partir del tipo penal o delito de la parte especial del Derecho penal. Y, en base a su definición y elementos constitutivos, se realiza el ejercicio interpretativo de encuadre (como decía un juez "veo si calza"). Desde la doctrina del razonamiento jurídico esta estructura formal de carácter deductivo se conoce como subsunción, ${ }^{72}$ la cual también es reconocida por los popios juzgadores.

En este ejercicio de adecuación típica respecto de un determinado supuesto de hecho, los juzgadores presentan dos posiciones bien marcadas. Aquellos que, desde la óptica del juzgamiento califican el hecho como configurativo de un solo contexto típico (utilizo esta expresión, antes que unidad de acción o hecho por las razones que se explicará después) y no hay problema concursal o concurrencia plural de normas penales y, por otro lado, quienes identifican un concurso con criterios bien identificados y aparentemente generalizados, los que obedecen en buena medida a aquellos principio, reglas y criterios entregados por la doctrina tradicional y que se reprodujieron en el apartado segundo de este trabajo.

Frente a estas dos posiciones distintas entre sí, existe como común denominador que caracteriza el juzgamiento: el proceso de exégesis por parte de los jueces, el cual permite afirmar la concurrencia de una sola norma legal o una pluralidad de estas (concurso). Este proceso, como relataban los juzgadores, es automático, parte de la lógica deductiva a la que se hizo alusión, y se logra tanto por la experiencia en la actividad de juzgamiento, como por los conocimientos técnicos que tienen sobre la materia.

Por otro lado, en el proceso de sentencing sobre concursos, los juzgadores evidencian dos cuestiones interesantes de destacar. La primera, en la cual los adjudicadores describen en la narrativa de la sentencia alguna situación concursal y, la segunda, en que omiten ese paso de exposición, siendo solo un ejercicio mental que se resuelve en ese plano como se dijo. Son prueba de lo primero el concurso real e ideal y, de lo segundo, el concurso aparente como resultó de las entrevistas. Concurso que se representa y se resuelve de manera mental. Sin perjuicio que también se manifestó en las entrevistas que era una institución jurídico difícil o compleja.

\footnotetext{
${ }^{71}$ POLITOFF et al. (2006), p. 183.

72 ATIENZA, (2005), pp. 118, 133 y 174; también ALEXY (2006), p. 93 y ss.
} 


\section{Polít. Crim. Vol. 16, № 31 (Julio 2021), Art. 2, pp. 30-61 [http://politcrim.com/wp-content/uploads/2021/04/Vol16N31A2.pdf]}

Finalmente, poder buscar una explicación de fuentes informales o extralegales, o de ideología o de creencias personales de los jueces en el proceso de juzgamiento al resolver una cuestión concursal también es complejo y, en términos generales, tampoco es del todo nítido que exista, aunque se presenta como aparente. En efecto, si bien los adjudicadores responden en sus sentencias a las categorías doctrinales tradicionales - las que sobre la materia también son dispares-, se distancian en el hecho de tener sus propias definiciones de estas instituciones jurídicas a partir de su íntima comprensión que se entrega por su propia experiencia. Es prueba de lo anterior, el hecho que en las simulaciones se detectó que respecto un mismo supuesto fáctico, algunos juzgadores evidenciaron un concurso real y otro grupo un concurso aparente de leyes penales. En circunstancias que uno supone, tanto legal como dogmáticamente, la comisión de varios ilícitos y, el otro, solo uno. Otro ejemplo sobre lo mismo, lo constituye la situación que algunos juzgadores tienen una concepción homogénea de acción y hecho, y otros una diametralmente distinta. Así, podemos concluir que los jueces probablemente tienen su propia práctica cultural, la que está referida a los conjuntos de significados o representaciones sobre algo, que puede estar o no compartida por los demás. En otras palabras, los jueces se representan ciertos significados concursales no necesariamente como lo señala la doctrina, sino de una forma particular, construido a partir de su propia comprensión y experiencia.

b) Conocer e identificar las cuestiones observadas por los jueces para determinar una unidad o pluralidad delictiva

Aquellos que no identificaron un problema concursal por considerar la concurrencia de un solo tipo penal lo hacen porque su experiencia los lleva a determinar la existencia de un solo delito frente al supuesto de hecho y, eventualmente distribuir y absorber dentro de él la probable concurrencia de más tipos penales. Aquí se ubica lo que se conoce dogmáticamente como concurso aparente. Sobre esta tipología como se dijo antes, ni siquiera se fundamenta o motiva en la sentencia - por regla general — conforme lo que relataron los juzgadores, lo que podría obedecer a que se trata de supuestos de aplicabilidad interna de normas jurídicas que solo obligan a determinar el singular tipo penal concurrente ${ }^{73} \mathrm{o}$ derechamente se omite por lo complejo de la materia como se explicará más adelante.

Ahora bien, si los juzgadores no reconocen un concurso, esto no quiere decir a prima facie que este no exista (particularmente tratándose de casos de concurso aparente), pues ellos aceptan - a lo menos implícitamente - la concurrencia eventual de dos o más normas incriminatorias en un mismo supuesto de juzgamiento, pero por aplicación de principios y criterios concursales, aquellas normas que podemos calificar de accesorias quedan subsumidas en la norma principal, que es la que finalmente prevalece. Así por ejemplo, se declaró la gravedad del tipo penal como un criterio envolvente (alternatividad); también el delito que su injusto consideraba a otro de menor entidad que finalmente lo absorvía (consunción); y el que decribía de mejor manera la conducta incriminada (especialidad). ${ }^{74}$ Existe de cierta manera una supresión mental de una norma que beneficia, privilegia o

\footnotetext{
${ }^{73}$ ARTAZA et al. (2019), p. 153 y ss.

${ }^{74}$ NOVOA (2010), p. 247; POLITOFF et al. (2006), p. 456; GARRIDO (2007), p. 435; CURY (2005), p. 667; ETCHEBERRY (2004), p. 123.
} 
reconoce la preferencia de otra norma jurídica. ${ }^{75}$ Esto es parte del ejercicio exegético automático que el juez realiza en el proceso de juzgamiento, el cual se ve acentuado o no, con la mayor o menor experiencia en la actividad jurisdiccional del juzgador.

Por otro lado, de acuerdo a las simulaciones y entrevistas los que califican la existencia de un problema concursal generalmente lo hacen, en primer término, sobre la base de reconocer una pluralidad de normas penales frente al caso concreto; como segunda alternativa por la existencia de distintos contextos situacionales (alusivos a contextos espacio-temporales); y finalmente por la producción de distintos resultados típicos que se presentan de manera independiente en la misma norma penal —un caso de reiteración_- probablemente.

Los juzgadores revelaron que la clásica asociación de sostener tantos delitos como acciones ejecutadas pierde trascendencia a la hora del juzgamiento. Si bien para una minoría esta premisa encuentra eco, lo cierto es que para una gran mayoría el delito no es sinónimo de acción, sino más bien de un contexto. Algunos también hacen sinónimo contexto de hecho, pero para algunos esta expresión parece más cercana a acción, — ahí que se haga necesaria su diferenciación conceptual-, como lo pregona el propio diccionario de la RAE ("Hecho: Acción u obra"). La característica del contexto situacional, nombre que describe el supuesto factico, se caracteriza por la concurrencia de una o diversas acciones que, en su conjunto, podrían definir típicamente el delito.

Las propiedades del contexto situacional, además de definir una cuestión concursal, también permiten dilucidar supuestos de unidad de delito. Estas, conforme lo expresado por los adjudicadores, estarían dadas por el espacio y tiempo en que se produce el ilícito, por la naturaleza del bien jurídico afectado (con un criterio cuantitativo), por la identidad de víctima y victimario, por la modalidad ejecutiva, y el dolo y/o propósito de la conducta del sujeto activo. Esto corroborá que los juzgadores siguen de una u otra forma los enunciados de la doctrina clásica antes descrita, aunque la interpretan probablemente no de la misma forma porque se arriba a soluciones dispares como se señaló anteriormente.

Es interesante como el dolo para algunos, elemento subjetivo del tipo - para otros elemento de la culpabilidad - , permite afirmar la existencia de una unidad delictiva, o bien ratificar la concurrencia de un concurso de normas legales, en tanto el sujeto activo dirija inequívocamente su voluntad a cometer un tipo penal o más de uno tratándose de una pluralidad delictiva. Situación que está conteste con lo declarado por parte importante de la doctrina. $^{76}$

En términos generales, los sentenciadores no están prejuzgados por algunas características subjetivas del autor, las que podrían condicionar sus decisiones en materia concursal. Si bien hubo excepciones en un solo juez, quien en la entrevista señaló que la situación de saber si estamos frente a un delincuente primerizo marca la posibilidad del eventual desplazamiento de un delito o la preferencia de otro para resolver una cuestión concursal, es un hallazgo

\footnotetext{
${ }^{75}$ MALDONADO, (2016), p. 567 y ss.

${ }^{76}$ GARRIDO (2007), p. 436; ETCHEBERRY (2004), p. 109 y ss.; CURY (2005), p. 650 y ss.
} 


\section{Polít. Crim. Vol. 16, № 31 (Julio 2021), Art. 2, pp. 30-61 [http://politcrim.com/wp-content/uploads/2021/04/Vol16N31A2.pdf]}

menor en términos cuantitativos, pero no por ello menos interesante, el que merece mayor estudio en la misma senda a objeto de corroborar esta hipótesis.

Sin perjuicio de lo anterior, la decisión de condena, en términos practicamente generales, develó probablemente una inclinación de la judicatura por la pena menos rigurosa. Situación que está conteste de cierta manera con la opciones penológicas que estudios empíricos sobre el tema han revelado ${ }^{77}$ Lamentablemente, hubiese sido util (lo cual no se hizo) correlacionar en las entrevistas la decisión del caso con con algunos aspectos filosóficos, como la finalidad del castigo, como se ha hecho en otros estudios. ${ }^{78}$

\section{c) Deteminar la complejidad que presentan los concursos en la labor de juzgamiento}

El proceso de decisión de cuestiones concursales a partir de la apreciación de los ejercicios de simulaciones, como de las entrevistas personales sostenidas con los adjudicadores, es de sumo complejo y evidencia un patrón de juzgamiento del todo heterogéneo. Poder establecer algunas generalidades también es difícil, salvo lo que dice relación con explicar que esta dispersión de criterios sobre un mismo asunto podría representar no tan solo la alta dificultad latente sobre las cuestiones concursales, sino también una inadecuada comprensión teórica - y porque no práctica— sobre estas temáticas.

Los casos simulados presentaron el proceso de interpretación de los jueces en la aplicación de la ley. En esa línea, la respuesta o solución jurídica sobre qué tipo penal debía aplicarse si bien era compartida - casi siempre - con ciertos matices, es patente que se llegaba a ella por caminos diversos. No obstante lo anterior, este patrón podría no existir en todos los casos que conforman nuestra realidad criminal y sería plausible sostener que el justiciable podría tener una respuesta dispar dependiendo del grado de comprensión y de intrepretación de la institucionalidad concursal por parte de la judicatura.

Las razones de este fraccionamiento de criterios, conforme lo observado en la resolución de casos simulados, se pueden situar en los siguientes problemas: a) La similitud que tienen los casos de unidad jurídica de acción, el concurso ideal y los casos de concurso aparente de leyes penales; b) Al grupo anterior de casos se suma el problema que se presenta entre el concurso real y el delito continuado. Saber cuándo hay un quebrantamiento normativo individual e independiente que requiere una sanción acumulativa, frente a una que es unitaria; c) Otra manifestación de conflicto, porque de base supone la realización de más de un tipo penal, es el que se presenta entre el concurso real y el concurso medial y; d) Finalmente, otro problema - aunque se crea inexistente - consiste en delimitar correctamente el ámbito de aplicación del concurso real y el ideal.

El primer nudo es el que se presenta ante la asimilación entre casos de unidad jurídica de acción, el concurso ideal y el aparente. Instituciones jurídicas que si bien son distintas, responden al principio de pena unitaria al fin y al cabo. Prácticamente en todos los casos se erigió este problema. Resultaba latente saber si estábamos ante la realización de un hecho

\footnotetext{
${ }^{77}$ HURTADO y JÜNEMANN (2001), p. 11; WILENMANN et al. (2019), pp. 456-490.

${ }^{78}$ MORALES y SALINERO (2020), pp. 319-341.
} 
punible en una sola oportunidad o en varias. Saber si casos en que formalmente concurría más de un tipo punible se debía identificar una única realización delictiva.

La colisión entre el concurso real y el delito continuado también estuvo presente en los ejercicios realizados (Caso Violación). Complejo escenario que ha traído históricamente este binomio y que representan los dos extremos frente a un caso concreto, por una parte, la acumulación material de penas por los distintos delitos y, por otro lado, la pena unitaria por uno solo. Quizás el inconveniente venga dado por la automaticidad del intérprete en encontrar la conocida identidad de los diversos elementos fundantes del delito continuado y en reducir el contexto situacional a un tiempo y lugar para dar por sentada este tipo de calificaciones.

Tratándose del problema entre el concurso real y el medial (Caso Violación y Homicidio calificado), probablemente el conflicto menos advertido en doctrina estaría constituido en la propia naturaleza jurídica del concurso medial (propiamente uno de carácter real), que tiene una identidad difusa de cara a su correcta y objetiva concreción. Tampoco se puede plausiblemente descartar la búsqueda de una solución menos rigurosa tras el delito medio, tal como ocurre a propósito del delito continuado.

Por otro lado, en el caso del conflicto entre concurso real e ideal (caso Bomba), viene probablemente dado porque tradicionalmente se ha construido que la división de ambos concursos radica en el número de delitos concurrentes y la definición propia de cada delito.

Así las cosas, los jueces dejaron en evidencia que la temática concursal si bien se construye a partir de hechos, finalmente es un problema jurídico o de derecho, que en la jerga del common law se conoce como casos dificiles de resolver. En efecto, determinar tanto una unidad o pluralidad delictiva implica un problema de interpretación que no se agota en una simple labor de deducción lógica del juzgador, puesto que siempre es posible que haya más de una norma que resulte aplicable y prevea una solución diferente para un caso concreto. ${ }^{79}$ Para resolver la cuestión, como explicaban los juzgadores, es necesario el conocimiento técnico de la dogmática para la labor subsunción. ${ }^{80}$

Para terminar, no podemos estar ajenos en comprender que el concurso de delitos es una temática compleja para el Derecho penal y la dogmática probablemente no lo ha hecho más fácil. Es suficiente prueba de lo anterior la constatación de la disparidad de criterios que se presenta al resolver casos semejantes. A su vez, la importancia de los concursos es abismante en la resolución de los casos que se presentan en la vida real. Por ello, ante una dispersión de posturas y posiciones en la judicatura, las posibilidades que el ajusticiado tenga una respuesta distinta ante un caso semejante es altamente probable. En consecuencia, urgen principios y explicaciones que ayuden a resolver los problemas o nudos que la práctica evidencia a la hora de solucionar casos concursales.

\footnotetext{
${ }^{79}$ ATIENZA (2005), p. 2. y ss.
}

${ }^{80}$ ALEXY (2006), p. 94. 


\section{Referencias bibliograficas}

ALEXY, Robert (2006): "Sobre la ponderación y la subsunción. Una comparación estructural", en: Pensamiento Jurídico ( $\left.{ }^{\circ} 16\right)$, pp. 93-111.

ARTAZA, Osvaldo; MENDOZA, Ricardo; ROJAS, Luciano (2019): "La consunción como regla de preferencia en el marco del concurso aparente de leyes", en: Revista de Derecho de la Pontificia Universidad Católica de Valparaíso ( $N^{\circ}$ 53), pp. 147-176.

ASHWORTH, Andrew (2010): Sentencing and Criminal Justice, $5^{\text {a }}$ ed. (Cambridge, University Press).

ATIENZA, Manuel (2005): Las razones del derecho. Teorías de la argumentación jurídica, $2^{\mathrm{a}}$ ed. (México, Universidad Nacional Autónoma de México).

ATIENZA, Manuel (2006): El Derecho como argumentación (Barcelona, Ariel).

CURY, Enrique (2005): Derecho penal. Parte general, $8^{\mathrm{a}}$ ed. (Santiago, Ediciones Pontificia Universidad Católica de Chile).

DE CASTRO RODRÍGUES, Andreia; SACAU Ana; DE OLIVEIRA, Jorge Quintas; GONCALVES, Rui Abrunhosa (2019): "Prison sentences: last resort or the default sanction?", en: Psychology, Crime \& Law (Año 2, No 25), pp. 171-194.

DROPPELMAN, Catalina; CARVACHO, Patricio; MATEO; María, VALENZUELA, Eduardo (2017): Estudio sobre los factores que influyen en las decisiones judiciales de la justicia juvenil en Chile, propuesta desarrollada en el marco del Concurso de Políticas (Santiago, Públicas UC).

GARLAND, David (1999): Castigo y sociedad moderna: un estudio de teoría social (Madrid, Siglo XXI).

GARRIDO MONTT, Mario (2007): Derecho penal. Parte general, $4^{\mathrm{a}}$ ed. (Santiago, Editorial Jurídica de Chile), tomo II.

ETCHEBERRY, Alfredo (2004): Derecho Penal. Parte General, $3^{a}$ ed. (Santiago, Editorial Jurídica de Chile), tomo II.

HOGARTH, John (1971): Sentencing as a Human Process (Canada, University of Toronto Press in association with the Centre of Criminology).

HURTADO, Paula; JÜNEMANN, Francisca (2001): "Estudio empírico de penas en Chile" en: Paz Ciudadana. Disponible en: https://tinyurl.com/ydroacj3 [visitado el 28/10/2019].

HUTTON, Neil (2006): "Sentencing as a Social Practice", en: ARMSTRONG, Sarah; MCARA, Lesley, perspectives on Punishment (Oxford University Press).

JESCHECK, Hans-Heinrich; WEIGEND, Thomas (2002): Tratado de Derecho penal. Parte general, $5^{a}$ ed. (Trad. Miguel Olmedo, Granada: Comares).

JOHNSON, Brian (2014): "Sentencing", en: TONRY, Michael. The Oxford Handbook of Crime and Criminal Justice (New York, Oxford University Press), pp. 696-729.

KENNEDY, Duncan (2004): Legal Education and the Reproduction of Hierarchy: A Polemic Against the System: A Critical Edition (New York, New York University Press).

MACKENZIE, Geraldine (2005): How judges sentence (Wales, Federation Press).

MAGUIRE, Neil (2014). "When is prison a last resort? Definitional problems and judicial interpretations", en: Irish Criminal Law Journal (Año 3, No 24), pp. 62-72.

MALDONADO, Francisco (2016): "Reiteración y concurso de delitos. Consideraciones sobre el artículo 351 del Código Procesal Penal a partir de la teoría general del concurso de delitos en el Derecho Chileno", en: Cárdenas, Claudia; Ferdman, Jorge 
(Coord.), El Derecho penal como teoría y como práctica. Libro en homenaje a Alfredo Etcheberry Orthusteguy (Santiago, Editorial Thomson Reuters), pp. 549-607.

MALDONADO, Francisco (2020): "Unidad de acción, unidad de hecho,y unidad de delito en el concurso de delitos", Revista Chilena de Derecho, 47 (3), pp. 733-755.

MILLER, April (2015): "The Effects of Gender, Race, and Age on Judicial Sentencing Decisions", en: Electronic Theses and Dissertations ( ${ }^{\circ}$ 8), pp. 1-57.

MORALES, Ana María; SALINERO, Sebastián (2020): “Cómo fallan y controlan la ejecución de las penas sustitutivas los jueces?", en: Revista de Derecho de Valdivia (Año $33 \mathrm{~N}^{\circ} 1$ ), pp. 319-341.

NOVOA, Eduardo (2010): Curso de Derecho Penal Chileno. Parte general, $3^{\mathrm{a}}$ ed. (Santiago, Editorial Jurídica de Chile), tomo II.

OLIVER, Guillermo (2013): “La exasperación de la pena en el concurso material de delitos: la reiteración de delitos de la misma especie", en: Revista de Derecho de Valdivia (Año 2, No 26), pp.167-188.

PFAFF, John (2006): "The Continued Vitaly of Stuctured Sentencing Following Blakely: The Effectiveness of Voluntary Guidelines”, en: UCLA Law Review (No 235), pp. 235-307.

POLITOFF, Sergio; MATUS, Jean Pierre; RAMÍREZ, María Cecilia (2006): Lecciones de Derecho Penal Chileno. Parte general, $2^{\mathrm{a}}$ ed. (Santiago, Editorial Jurídica de Chile),

POSNER, Richard (2011): Cómo deciden los jueces (Barcelona, Marcial Pons).

SANZ, Ángel (1986): El concurso de delitos: aspectos de política legislativa (Valladolid, Universidad de Valladolid).

SPOHN, Cassia (2008): How do judges decide? The Search for Fairness and Justice in Punishment (USA, Arizona State University).

TONRY, Michael (2016): Sentencing Fragments (New York: Oxford University Press).

ULMER, Jeffery (2012): "New Directions in Sentencing", en: Justice Quaterly (Año 1, No 29), pp. 1-40.

VELASQUEZ, Javier (2018): Doing Justice: Sentencing Practices in Scottish Sheriff Courts. Tesis doctoral (Edimburgo, University of Edimburgh).

VIVES, Tomás (1981): La estructura de la teoría del concurso de infracciones (Valencia, Universidad de Valencia).

VON HIRSCH, Andrew; ASHWORTH, Andrew (2005): Proportionate Sentencin (New York, Oxford University Press).

WILENMANN, Javier; MEDINA, Francisco; OLIVARES, Esteban; DEL FIERRO, Nicolás (2019): "La determinación de la pena en la práctica judicial chilena", en Política Criminal (Nº 12 , Año 2), pp.456-490. 